\title{
O uso do medicamento na percepção do usuário do Programa Hiperdia
}

\author{
The use of medication in the perception of users Hiperdia Program
}

Patrícia Aparecida Baumgratz de Paula ${ }^{1}$

Auta Iselina Stephan-Souza ${ }^{2}$

Rita de Cássia Padula Alves Vieira ${ }^{3}$

Therezinha Noemides Pires Alves ${ }^{4}$

${ }^{1}$ Instituto de Medicina Social, Universidade do Estado do Rio de Janeiro. Rua São Francisco Xavier 524, Pavilhão João Lyra Filho, $7^{\circ}$ andar, blocos D e E, e $6^{\circ}$ andar, bloco E, Maracanã. 20550-900 Rio de Janeiro RJ. pabpaula@ig.com.br pabpaula@ig.com.br ${ }^{2}$ Faculdade de Serviço Social, Universidade Federal de Juiz de Fora. ${ }^{3}$ Faculdade de Farmácia, Universidade Federal de Juiz de Fora.

4 Instituto de Ciências

Biológicas, Universidade

Federal de Juiz de Fora.

\begin{abstract}
This article discusses the question of access to medication as a social right, investigating how users registered in the Hiperdia program perceive their access to medication. To achieve this, the process of "medicalization" experienced by Brazilian society today was assessed, highlighting the influence that this process has on access to medication, prejudicing the achievement of universal and equalitarian access. Using a technique recommended by qualitative research, focal groups with Hiperdia users in the basic health service of Juiz de Fora, Minas Gerais, Brazil, were set up. The survey emphasizes the perception that these users have with respect to their rights related to essential medication. In this process, their beliefs, knowledge, attitudes, difficulties, fears, doubts and anxieties concerning the use of essential medication are investigated, as well as their viewpoints on the disease(s) they suffer from. Among the results obtained, it was revealed that the majority of the users of basic health units do not consider that they have rights and that access to medication as a constitutionally-assured social right is far from being implemented in the Brazilian public health service today.
\end{abstract}

Key words Medication use, Access, Basic services, Health system, Right to health
Resumo O presente artigo discute a questão do acesso aos medicamentos como direito social, a partir da investigação de como o usuário do Hiperdia percebe seu acesso aos medicamentos. Para tanto, aborda o processo de medicalização vivenciado pela sociedade brasileira contemporânea, ressaltando a influência que esse processo exerce sobre o acesso aos medicamentos, comprometendo a concretização do acesso universal e igualitário. Utilizando técnica preconizada pela pesquisa qualitativa, foram realizados grupos focais com os usuários do Hiperdia nas unidades básicas de saúde de Juiz de Fora, Minas Gerais. O estudo enfatiza a percepção que esses usuários têm de seus direitos em relação ao acesso aos medicamentos essenciais. Nesse processo, investigam-se suas crenças, saberes, atitudes, dificuldades, medos, dúvidas, anseios com relação ao uso dos medicamentos essenciais, bem como a visão sobre $a(s)$ doença(s) que os acomete $(m)$. Entre os resultados alcançados, evidenciou-se que a maioria dos usuários das unidades básicas de saúde não se considera portador de direitos e que o acesso aos medicamentos como direito social garantido constitucionalmente está longe de ser efetivado no cotidiano do serviço público de saúde brasileiro.

Palavras-chave Uso de medicamentos, Acesso, Unidades básicas, Sistemas de saúde, Direito à saúde 


\section{Introdução}

A legitimação do Sistema Único de Saúde (SUS), concebido na Constituição Federal ${ }^{1}$, representou um avanço no campo da saúde brasileira, já que, a partir desse período, os usuários dos serviços públicos de saúde passaram a ser reconhecidos como sujeitos portadores de direitos. Anteriormente a esse período, o acesso à saúde ocorria por meio da benesse, compreendida como a oferta de atendimento "gratuito" à população necessitada nos serviços públicos de saúde, e também através de relações contratuais, isto é, por meio da contribuição à previdência social. Essa situação de destituição de direito propiciava a cidadania incompleta - nos dizeres de $\mathrm{Bahia}^{2}$, uma "cidadania de baixa intensidade" -, condição em que os indivíduos encontram-se subjugados em uma sociedade na qual não conseguem se expressar como sujeitos sociais.

Segundo Telles ${ }^{3}$, a discussão dos direitos sociais emerge das contradições vivenciadas pelo mundo contemporâneo, e na sociedade brasileira essas contradições se manifestam de várias maneiras. De um lado, tem-se enormes discrepâncias de natureza socioeconômica, que se traduzem, entre outras vias, através da obtenção de privilégios, intensificando desigualdades com reflexos claros na aquisição dos medicamentos essenciais para a manutenção da saúde. De outro lado, temse a inclusão que se realiza pelo consumo, estímulo à competitividade e ao individualismo nas relações sociais em detrimento do coletivo, proporcionando à população uma situação de desvalia, de não proteção e de não reconhecimento do direito a ter direitos, como acontece no âmbito da distribuição dos medicamentos.

Nessa perspectiva, a competência do Estado, estabelecida constitucionalmente, de garantir o acesso universal aos bens e serviços públicos transforma-se em atendimento mínimo ante as necessidades básicas vivenciadas pela população. Este trabalho, ao focalizar o acesso aos medicamentos no Brasil como direito social, pretende discutir os fatores intrínsecos que podem vir a comprometer a materialização do direito à saúde.

Dentre esses fatos, cita-se o não acesso a um atendimento médico-assistencial, incluindo o acesso aos medicamentos, e o processo de "medicalização" que a sociedade brasileira vem vivenciando na contemporaneidade. Nesse contexto, os usuários dos serviços de saúde são vistos como potenciais consumidores de bens e serviços de saúde e não como cidadãos portadores de direitos. Tal fato contribui para que a efetivação do direito à saúde, como direito social alicerçado na igualdade, torne-se ameaçada - isto é, o direito passa a ser interpretado tomando com base critérios de exclusão, propiciando a reposição de privilégios e comprometendo a consolidação do Sistema Único de Saúde (SUS).

Illich ${ }^{4}$ entende o processo de medicalização como sendo a invasão da medicina e do aparato tecnológico na vida das pessoas, ao longo do tempo. Nessa perspectiva, a vida dos indivíduos, ou as etapas dela, passa a ser alvo de cuidados e estratégias intervencionistas específicas, independentemente da existência concreta de sinais ou sintomas mórbidos.

Essa situação tende ao agravamento devido ao modelo biomédico, que propõe uma visão mecânica do corpo humano. Segundo esse modelo, o corpo é visto como um somatório de partes, sugerindo que a interpretação da doença seja apenas baseada na correlação de causa-efeito, sem, muitas vezes, levar em consideração os demais fatores inerentes a esse processo. É provável que a expressão mais acabada das distorções e conseqüências concretas do modelo biomédico, reducionista, de abordagem da saúde e da doença na vida dos indivíduos resida no que se convencionou designar como "medicalização"s.

Tudo isso reforça o processo de medicalização, ao estimular o uso exagerado de novas tecnologias, principalmente em relação à produção e ao consumo de medicamentos. Aliados, a medicalização e o modelo biomédico transformam a saúde em mercadoria passível de ser consumida pela população, ao incentivar o consumo de bens e serviços de saúde, inclusive de medicamentos, visando aos interesses do mercado, sem levar em conta os excessos que vêm caracterizando sua utilização. Por sua vez, a situação mundial, no tocante ao acesso aos medicamentos essenciais, mostra que 1,7 bilhão de pessoas não têm acesso regular a esses insumos, sendo que $80 \%$ delas residem nos países pobres ${ }^{6}$.

Outro fator que envolve o acesso aos medicamentos no Brasil é a presença, na sociedade brasileira, de uma cultura de troca de favores, de manipulação política, de exercício de poder e de clientelismo por parte de alguns gestores de saúde, em oposição à cultura de direito.

$\mathrm{Na}$ sociedade brasileira, os problemas assinalados com respeito ao acesso são significativamente importantes, em especial quando se leva em consideração a hipertensão arterial e o diabetes mellitus. De acordo com a estimativa do Ministério da Saúde ${ }^{7}$, dos 16,8 milhões de brasileiros que sofrem de hipertensão arterial, somente 7,7 milhões 
estão cadastrados no Sistema Único de Saúde (SUS). Em relação ao diabetes, de aproximadamente 5 milhões de portadores da doença, apenas 2,6 milhões são pacientes do sistema. Logo, o acesso aos medicamentos usados para tratar tais enfermidades fica comprometido, uma vez que, apesar de estar garantido constitucionalmente, nem todos os pacientes têm esse acesso viabilizado.

Este estudo pretende ir ao encontro dessas questões ao abordar o acesso aos medicamentos a partir da percepção dos usuários de um programa de hipertensão arterial e diabetes mellitus. O foco nessas doenças deve-se ao perfil da morbimortalidade ocupado por elas em nível mundial e no Brasil, acrescido do elevado custo médico-social associado a seu tratamento. Essas doenças conduzem a altas taxas de óbitos, de internações e de aposentadorias precoces, podendo gerar outras complicações conjugadas, como o acidente vascular cerebral (AVC), as doenças renais crônicas (DRC) e as doenças cardiovasculares (DCV), que representam 31\% do total de óbitos associados a causas conhecidas no país ${ }^{8}$.

Além disso, tanto a hipertensão arterial como o diabetes foram doenças motivadoras do Plano de Reorganização da Atenção à Hipertensão Arterial e ao Diabetes Mellitus (PRAHADM), criado em 2001 pelo Ministério da Saúde (MS). Este plano tem como finalidade principal o tratamento e o acompanhamento dos usuários das unidades básicas de saúde (UBS) do SUS. Isso é feito através de um sistema de cadastro informatizado disponibilizado pelo Datasus, denominado de Cadastro e Acompanhamento de Hipertensos e/ ou Diabéticos - Hiperdia, sistema integrado ao Cartão Nacional de Saúde (CNS).

Nesse cenário, a análise do acesso aos medicamentos também requer o entendimento dos sentidos que eles adquirem na sociedade brasileira contemporânea. Os medicamentos podem apresentar-se como agente quimioterápico, como mercadoria e como símbolo, todas essas funções consideradas indissociáveis, principalmente quando se leva em consideração o processo de medicalização vivenciado por essa sociedade. Lefèvre $^{9}$ apontou a importância de se entender o medicamento, localizando-o em regiões mais críticas do tecido social, como uma mercadoria capaz de traduzir um processo de reificação da saúde; como um agente que alivia, cura e controla doenças; e como símbolo que permite que a saúde (ou mais precisamente a saúde "biologizada") esteja nele representada.
Para Zubioli ${ }^{10}$, o medicamento é imprescindível e tem relevância crescente na atenção à saúde. Entretanto, suas características próprias permitem que se apliquem a ele as regras do jogo predominantes no livre mercado. Deve-se reconhecer, ainda segundo o autor, que muito pouco se fez para a compreensão do medicamento como bem social. Ao ser considerado como uma mercadoria, o medicamento deixa de exercer o papel central na política de saúde brasileira, baseada nos princípios e nas diretrizes do SUS, reforçando a dominação da saúde pública pelos interesses do mercado.

Marin et al. ${ }^{11}$ afirmam que, ao ser considerado como bem de consumo e não como insumo básico de saúde, o medicamento passa a ser um objeto desvirtuado no Sistema de Saúde, inviabilizando o desenvolvimento de um enfoque que priorize o cuidado com a terapêutica medicamentosa, envolvendo nessa concepção a formação de profissionais, o processo de educação continuada, a orientação à população e o acompanhamento do uso adequado e racional dos medicamentos ${ }^{11}$.

Como um bem social inserido na atenção à saúde, o medicamento requer uma regulação das leis da oferta e da procura do mercado farmacêutico, resultando em uma política pública, centralizada no papel do Estado como agente formulador e regulador, garantindo o cumprimento das normas legais e das ações de vigilância. É preciso, ainda, atuar com firmeza para que o conceito de medicamento como bem social se traduza em realidade ${ }^{10}$.

Supõe-se que a compreensão do medicamento como bem social a serviço de uma coletividade poderá propiciar a diminuição do processo de medicalização que a sociedade brasileira contemporânea vivencia, influindo na política pública de saúde com enfoque no acesso universal e igualitário a esses insumos.

Nessa perspectiva, torna-se de suma importância o entendimento da representação social do medicamento, através da investigação - sob o enfoque dos direitos sociais - de como os usuários de algumas UBS de Juiz de Fora compreendem $o$ acesso ao medicamento, enfatizando-se sua percepção sobre seus direitos, suas crenças, seus saberes, suas dificuldades e dúvidas com relação ao uso dos medicamentos essenciais, bem como a visão sobre a(s) doença(s) que os acomete(m).

Acredita-se que a compreensão do acesso aos medicamentos como direito social propiciará compreender o usuário como um cidadão portador de direitos e não como um simples cliente dos serviços de saúde. 


\section{O Hiperdia}

Esse cadastro fornece as informações necessárias para a aquisição, a dispensação e a distribuição dos medicamentos usados no tratamento da hipertensão arterial e do diabetes mellitus de modo regular e sistemático aos usuários das UBS. Como parte dele, foi criado em 2002 o Programa Nacional de Assistência Farmacêutica para Hipertensão Arterial e o Diabetes Mellitus, que tratava da organização, assistência, prevenção, promoção à saúde, vinculação dos usuários à rede básica de saúde do SUS, bem como da implementação de programas de educação permanente para essas doenças e para os demais fatores de risco para a DCV.

Um dos objetivos desse programa consiste no repasse dos medicamentos aos portadores de hipertensão arterial e de diabetes mellitus. Os medicamentos utilizados para o tratamento dessas doenças são distribuídos pelo SUS. São eles: Captopril 25 mg, Hidroclorotiazida 25 mg e Cloridrato de Propanolol $40 \mathrm{mg}$ (anti-hipertensivos); Insulina NPH-100, Glibenclamida 5 mg e Metformina $850 \mathrm{mg}$ (hipoglicemiantes).

O processo de aquisição e de envio desses insumos para as UBS é baseado na estimativa das doenças, bem como no esquema terapêutico proposto. O financiamento desse programa baseiase no repasse fundo a fundo dos recursos financeiros somados ao Piso de Atenção Básica (PAB), pós-pactuação tripartite, feita pelo gestor municipal. Também pode ocorrer o envio de medicamentos, por meio da Farmácia Popular, às áreas atendidas pelo Programa Saúde da Família.

No município de Juiz de Fora, Minas Gerais, a implantação do Hiperdia ocorreu em março de 2003, estando vinculado ao Serviço de Controle da Hipertensão Arterial, do Diabetes Mellitus e da Obesidade (SCHDO), da Secretaria Municipal de Saúde, Saneamento e de Desenvolvimento Ambiental (SSSDA). Para receber os medicamentos nas UBS, os pacientes deveriam estar cadastrados no Sistema de Informação da Hipertensão e Diabetes (SISHiperdia).

No ano de 2006, existiam aproximadamente 33.000 pacientes cadastrados pelo Hiperdia no município de Juiz de Fora ${ }^{12}$. Os critérios de provisão e de dispensação dos medicamentos baseavam-se em uma planilha feita pelas UBS e entregue à coordenadoria do SCHDO, contendo a quantidade necessária de medicamentos para o atendimento dos usuários. Após a análise dessa listagem, realizava-se a elaboração do pedido para o almoxarifado. Entretanto, a provisão dos me- dicamentos é dificultada por vários fatores, dentre eles a demora no prazo de entrega pelo MS e pela Secretaria Estadual de Saúde (SES), ocasionando dificuldades na obtenção de medicamentos essenciais nesse município.

\section{Método}

Este estudo decorre de uma pesquisa qualitativa, realizada em algumas UBS do município de Juiz de Fora (JF). O método foi escolhido por privilegiar, essencialmente, "a compreensão dos comportamentos a partir da perspectiva dos sujeitos da investigação"13.

Após a aprovação pelo Comitê de Ética da Universidade Federal de Juiz de Fora (UFJF), teve início a primeira etapa da pesquisa nas UBS/JF, que se constituiu de uma observação de campo com duração de aproximadamente seis meses. Foram anotados no caderno de campo as falas, os comportamentos e atitudes dos usuários (diabéticos e/ou hipertensos) à espera do atendimento ambulatorial.

$\mathrm{Na}$ expressão de Turato $^{14}$, o investigador qualitativo, quando vai para o campo estudar "as coisas", não é a elas em si que ele vai se ater. Em se tratando de pesquisa qualitativa, as "coisas" são as pessoas ou as comunidades em sua fala e em seu comportamento. E mais é sempre no setting natural que ocorre o estudo, e nunca em um ambiente reprodutor de situações, como laboratórios, gabinetes, etc. Mas, se não é a coisa que lhe interessa, o alvo do interesse do estudioso é, por outro lado, o significado que essas coisas ganham, ou melhor, as significações que um indivíduo em particular ou um grupo determinado atribuem aos fenômenos que lhes dizem respeito ou vivenciam ${ }^{14}$.

$\mathrm{Na}$ segunda etapa foi utilizada a técnica de grupos focais, de modo a complementar os dados obtidos anteriormente com a observação de campo. Para Kitzinger ${ }^{15}$, os grupos focais consistem no desenvolvimento de um tipo especial de entrevista, a entrevista em grupo, na qual se valoriza a comunicação entre os participantes da pesquisa para que se possa produzir dados.

Essa técnica foi aplicada a um grupo de aproximadamente dez usuários que fazem parte do Hiperdia em cada uma das UBS escolhidas. Os grupos focais tiveram a duração de aproximadamente quarenta minutos, e o gravador foi utilizado como instrumento de registro dos dados. Os dados foram analisados a partir da categoria "representação social". Segundo Minayo ${ }^{16}$, as Representações Sociais enquanto censo comum, 
idéias, imagens, concepções e visão de mundo que os atores sociais possuem sobre a realidade, são um material importante para a pesquisa.

Os participantes foram estimulados a trocarem opiniões sobre os seguintes elementos temáticos: "convivência com a doença", "percepção dos medicamentos" e "compreensão acerca do acesso ao medicamento como direito ou como benesse".

Após a realização dos grupos, as gravações foram transcritas e iniciou-se a análise dos dados obtidos, que foram organizados através de categorias: "significação da doença", "significado do medicamento" e "isão do acesso aos medicamentos". A interpretação dos dados teve como fundamento a inserção das pesquisadoras no ambiente natural dos participantes da pesquisa e na literatura selecionada.

\section{Resultados}

\section{Significação da doença}

Uma das categorias que mereceram destaque foi a "significação da doença". Ao se levar em consideração a visão da saúde e da doença como sendo um processo construído socialmente, percebe-se que esta produz diferentes interpretações, significações e leituras dependendo do cenário em que se encontra. $\mathrm{Na}$ expressão de Ferreira ${ }^{17}$, as sensações corporais experimentadas pelos indivíduos e as interpretações médicas dadas a estas sensações serão feitas de acordo com códigos específicos a estes dois grupos. A capacidade de pensar, exprimir e identificar estas mensagens corporais está ligada a uma leitura que procura determinada significação. Esta leitura está na dependência direta da representação de corpo e de doença vigente em cada grupo. Neste sentido, o corpo pode ser tomado como um suporte de signos, ou seja, suporte de qualquer fenômeno gerador de significação e sentido.

De acordo com o que foi constatado no campo de pesquisa, as indagações não se calam na mente dos usuários dos serviços de saúde, contribuindo para a criação de significações próprias a respeito do processo saúde-doença a que estão submetidos, o que remete a Camargo Jr. ${ }^{18}$, que afirma: Estar doente não implica perda das faculdades da razão - este princípio aparentemente tão óbvio é sistematicamente desconsiderado no dia-a-dia da prática médica, infelizmente.

Esse tipo de prática poderia explicar a concepção equivocada sobre o estado de saúde, que muitos usuários das UBS demonstram. Muitos deles desconhecem o nome da doença que os acomete, suas causas, seu controle, entre outros aspectos, como demonstram os seguintes depoimentos:

É difícil você ter um problema e não saber o que é, não ter explicação (usuária hipertensa do hiperdia, que se indaga sobre o porquê do surgimento da hipertensão arterial, após a menopausa, ao esperar pelo atendimento médico).

Eles nunca chegaram a explicar o porquê, eu olhando assim pra mim, estou aceitando que pode ser de família, sendo que minha mãe era hipertensa, minha tia era hipertensa, meu pai eu nunca soube por que ele morreu novo e eu era bem menina. Mas minha mãe era hipertensa e diabética; quando ela fez dez anos que era diabética ela teve cinco AVC. Segundo os médicos, ela não teve sequela igual quando ela teve o quarto, porque não era diabética, então, diz que pressão e colesterol, tudo anda junto, devido o quê? Não explica.

Não entendo por que se leva susto a pressão sobe e se fica nervosa a pressão sobe. Sei que tem limites na alimentação, isso eu sei, mas de onde vem, como vem isso eu não sei, não.

Nesse sentido, afirma Boltanski ${ }^{19}$ que a recusa de fornecer ao doente um mínimo de informações sobre seu corpo e doenças, em função essencialmente de impedi-lo de manter com o corpo uma relação científica e reflexiva com a doença, essa atitude tem conseqüências inversas, pois leva o doente à obrigação de construir com seus próprios meios, ou seja, "com os recursos de bordo", o discurso sobre a doença que o médico não transmitiu.

A expressão "Diabetes é açúcar no sangue" foi muitas vezes registrada nos depoimentos dos diabéticos e/ou hipertensos, sugerindo que a concepção do diabetes indica uma relação, no imaginário dos pacientes, entre a diminuição das taxas de glicose sanguínea e a redução da ingestão de doces (açúcares). Todavia, essa doença está associada a numerosos fatores como obesidade, alimentação rica em carboidratos ${ }^{20}$. Da mesma forma, a expressão "Tenho gordura no sangue", também frequente nas falas dos pacientes, está relacionada frequentemente a uma alta taxa de colesterol. Entretanto, sabe-se que a hipertensão arterial consiste na elevação da pressão arterial, sendo uma doença multifatorial, isto é, existem vários fatores que podem desencadeá-la; entre eles, citam-se: sexo, etnia, álcool, obesidade, sedentarismo, alimentação (excesso de sal) e os fatores socioeconômicos, existindo uma maior prevalência da doença nas classes baixas ${ }^{21}$.

Em relação à concepção sobre a hipertensão arterial e o diabetes, várias falas dos usuários das UBS apontam para uma situação de perigo iminente, demonstrado pela visão de medo, de pro- 
longamento e de durabilidade da doença, mesmo que os sintomas ainda não tenham se manifestado concretamente no dia a dia dos pacientes. É o que pode ser observado nos depoimentos a seguir:

Esta doença mata.

A pressão é doença para toda a vida.

Se bobear, a pressão derruba a gente.

As doenças também são vistas como algo sujo, impuro. Esse tipo de concepção reafirma o lado negativo da doença, como prática hegemônica na sociedade brasileira, que propiciará a visão da saúde como mercadoria. Segundo Lefèvre ${ }^{9}$, a saúde só passa a ter sentido, no contexto de uma sociedade alienada, dominada pela mercadoria, quando acoplada à doença, ou à ameaça de morte, ou à dor, ou ao desprazer, ou à feiúra, ou à fraqueza.

$\mathrm{O}$ relato a seguir sugere essa apreensão em relação à hipertensão arterial e ao diabetes melittus: Eu tenho estas imundices (usuária hipertensa e diabética do Programa Hiperdia, enquanto esperava para mostrar os resultados dos exames).

\section{Significado do medicamento}

Outro aspecto destacado nos depoimentos diz respeito ao "significado do medicamento". O medicamento pode ser entendido como agente quimioterápico, como produto tecnológico, testado empiricamente, que encerra o princípio ativo nas mais diversas formas farmacêuticas (comprimidos, xaropes e outras), nas quantidades necessárias para se obter o efeito desejado, isto é, resguardar ou proporcionar a saúde. ...o medicamento é a fórmula (química) materializada do Estado de BemEstar, ou seja, da Saúde. Mais precisamente, o medicamento é a fórmula (química) do Estado de NãoMal-Estar ou de Não-Agravo [...] enquanto símbolo, o medicamento concentra saúde .

Ao se levar em consideração a semântica da palavra "símbolo" como alguma coisa que pode ser representada ou substituída por outra, temse a apreensão da função exercida pelos medicamentos no imaginário dos usuários; ou seja, o medicamento é visto por eles como algo concreto, que encerra o poder de restabelecer e de oferecer a saúde. Nesse sentido, merecem destaque as seguintes falas:

O remédio para mim é igual à carne do dia (paciente hipertenso do Hiperdia, ao adquirir os remédios na farmácia da UBS).

Se eu parar de tomar eu morro.

O remédio é uma necessidade (paciente hipertenso do Hiperdia, enquanto aguardava atendimento médico).

Todavia, o uso regular do medicamento pode remeter a uma situação de obrigação para os pa- cientes. Conforme Lefèvre", O remédio é, portanto, uma obrigação e na obrigação está contida a pílula amarga. Os depoimentos a seguir expressam isto:

Estou cansado de tomar muito remédio para a pressão.

A gente passa o dia inteiro tomando remédio, se bobear à noite a gente também toma.

É um remédio que praticamente você tem que tomar para o resto da vida esse de pressão, por exemplo. Tem que tomar porque se não tomar a pressão sobe?.

De acordo com Oliveira et al..$^{22}$, Magia, mistério, ciência e mercado sempre disputaram a percepção da população com relação aos efeitos terapêuticos dos medicamentos. Os dados coletados reforçam o fato de os medicamentos apresentarem-se no imaginário dos usuários revestidos dessa mistura de significações:

O remédio de diabete é pra queimar açúcar, e o de pressão eu não entendo.

Me sentia seca, parece que o remédio tira o líquido do sangue.

Para Lefèvre' ${ }^{9}$ a obtenção de um alto grau de eficiência simbólica acontece quando ocorre a cura, quando existe a saúde definitiva. Em contrapartida, com o controle, existe um baixo grau de eficiência simbólica, isto é, a saúde tem que ser reconquistada permanentemente, ou seja, com o controle, efetuado pelo medicamento (entre outros recursos), o indivíduo não deixa de ser doente: ele deixa de estar, de ficar doente ${ }^{9}$. Os relatos a seguir confirmam essa percepção:

Eu penso que ele representa não a cura, mas representa um controle que ele não pode ser paralisado com o tratamento.

O remédio controla, mas eu já cheguei à conclusão, porque eu tenho pressão alta há mais de vinte anos, eu acho que não cura, não, não tem cura, não. Eu já tomei alguns remédios e não curei, não tem cura.

Sem o remédio eu não tenho como controlar isso aí.

Em alguns casos, de acordo com o contexto em que está inserido, o medicamento passa a ter sentido ambíguo, não representa a obtenção da saúde, mas é visto como algo ruim para o organismo. Sabe-se que todo medicamento pode ser benéfico ou maléfico para a saúde, dependendo da dose a ser usada e da forma de administração. Assim, a expressão "males que vêm para bem" exemplifica esta ambiguidade?. O depoimento a seguir revela esta percepção em relação ao medicamento: Aí eu levanto para tomar o veneno 9 .

Do mesmo modo que os usuários das UBS têm uma concepção pessoal do processo saúde- 
doença, demonstrando, em muitas situações, desconhecimento deste, eles também possuem uma visão dos medicamentos que usam, empregando uma linguagem própria para descrevê-los e identificá-los.

Boltanski ${ }^{19}$ já alertava para o fato de que os remédios eram apresentados às classes baixas por meio de uma linguagem inacessível: o problema que tem a resolver é o seguinte: como classificar, distinguir e designar objetos, remédios, cujas denominações científicas, freqüentemente formadas sobre um radical grego ou latino, não têm para eles nenhum significado, apresentam-se habitualmente sob uma forma fônica complexa e certa maneira com palavras de uma lingua estrangeira e dos quais, além disso, não conhecem nem o princípio de eficácia e muitas vezes - principalmente quando vários remédios são prescritos durante uma mesma doença - nem mesmo sua função específica.

Quase três décadas depois, as palavras do autor permanecem válidas. Como têm dificuldade em pronunciar os nomes dos medicamentos, os usuários do SUS utilizam referências a cores e tamanhos diversos para identificá-los, como demonstram os depoimentos a seguir:

O vermelhinho me fez mal, parei de tomar por conta própria. O médico tinha me passado ele para não precisar de tomar Lo... [Losartan], mas eu passei mal e preferi voltar a comprar e não passar mal.

Eu tomo Nicotiazina - não sei falar direito, não (disse uma paciente hipertensa do Hiperdia, ao fazer referência ao medicamento anti-hipertensivo hidroclorotiazida).

Uns comprimidinhos pequenos. Tem um nome comprido também.

\section{Visão do acesso aos medicamentos}

Outra categoria destacada foi a "visão do acesso aos medicamentos". A compreensão dessa categoria requer o entendimento de uma das dimensões do acesso aos serviços de saúde, a capacidade financeira, proposta por Penchansky e Thomas $^{23}$. Segundo os autores, esta se relaciona à capacidade de pagamento pelos serviços. Entende-se que a capacidade financeira pode também abranger o acesso aos medicamentos.

Ademais, por se inserir no acesso à saúde, a discussão do acesso aos medicamentos também deve contemplar os fatores políticos, sociais e econômicos implicados na busca de medicamentos realizada pelos usuários dos serviços de saúde. [...] o acesso aos medicamentos envolve uma complexa rede de atores, públicos e privados, que desempenham diferentes papéis em função do contexto econômico, politico e social dos diferentes países [...] a relação entre o preço do cuidado e a capacidade dos usuários de pagar é uma questão central do acesso ${ }^{24}$.

Quando se leva em consideração os medicamentos essenciais distribuídos pelo governo federal por meio dos programas preconizados pelo MS, percebe-se que os usuários do hiperdia nas UBS de Juiz de Fora estão satisfeitos em relação à possibilidade de obter tais medicamentos nesses locais. Tal concepção é justificada pela baixa condição socioeconômica de que esses usuários desfrutam, como se pode observar nos depoimentos colhidos durante a realização dos grupos focais.

Olha, isso ajuda a gente, porque eu sou uma pessoa de classe assim, nem média e nem social, entendeu? Então eu sou do lar, então isso ajuda a gente e muito, porque nem sempre tem dinheiro pra comprar ou muitas das vezes você tem que pedir um empréstimo... Mesma coisa, você está bem $e$, de repente, se sente mal e aí você vai ao médico ele passa a receita e aí você vem no posto e não tem, aí você tem que comprar, se você quer melhorar tem que comprar. Não tem outro jeito de não comprar medicação e como é de uso contínuo, se não tiver... Você tem que comprar, você pensa assim que se não tomar vai se sentir mal, quero dizer, tendo ou não você tem que comprar. O hipertenso, o diabético...

Melhor, né? Não precisa tirar o dinheirinho pra pagar. Do dinheirinho do leite que está caro pra caramba. Eu sempre ganho aqui o [...] eu sempre ganho. Agora, o outro não tem, só quando tem amostra grátis.

É bom, quando a gente chega ali e tem tudo, fica até alegre.

A insuficiência, em alguns casos, do fornecimento dos medicamentos distribuídos pelo Hiperdia, acrescida do não acesso dos usuários a um grande número de medicamentos que são prescritos para as complicações associadas à hipertensão arterial e ao diabetes mellitus, também foi um problema percebido, como pode ser constatado nos seguintes depoimentos:

Se a médica passar o remédio caro [sinvastatina, para colesterol], vou chorar, não tenho dinheiro para comprar. A última vez custou $R \$ 50,00$.

No meu caso eu tomo Omeprazol, porque vem quatorze comprimidos e está vinte e nove reais, tem que tomar todo dia, se não tomar, o estômago fica ruim e aí não tem jeito. Você escolhe, com dinheiro no bolso e com dor ou então você fica duro sem dor.

Porque eles mandam só os mais baratos, e os caros mesmos eles não mandam.

Convivendo com essa realidade, os pacientes, na maioria assalariados ou aposentados, utilizam diversos artifícios para sanar a dificuldade em obter os medicamentos, uma vez que necessi- 
tam diariamente deles. Para tanto, eles recorrem aos vizinhos, aos amigos, aos parentes e ao fiado na farmácia a fim de adquiri-los. Outra prática comum é o recebimento de amostras grátis ou de doações, como demonstram os depoimentos a seguir:

A minha filha que está pagando pra mim. O meu marido trabalha por conta própria e tem dia que tem dinheiro e tem dia que não tem.

Eu geralmente procuro um lugar que eu possa pegar amostra grátis. Eu sempre pego amostra grátis, sou conhecido na farmácia.

Eu tomo só o de pressão porque o pagamento não saiu ainda.

A indústria farmacêutica mundial mobiliza um mercado de bilhões de dólares, e ao se estabelecer uma relação entre o consumo de medicamentos e a distribuição da população no mundo, verificase que ocorre uma desigualdade no acesso aos medicamentos. Segundo Oliveira et al. ${ }^{22}, 80 \%$ da produção de medicamentos são consumidos por $18 \%$ da população que vive em países desenvolvidos da América do Norte e da Europa e no Japão.

Entretanto, os medicamentos genéricos, cujo preço é até $40 \%$ menor que os de marca, trouxeram certo alívio para os doentes crônicos, gerando uma boa economia financeira ${ }^{25}$. Logo, esse tipo de medicamento com qualidade assegurada por testes laboratoriais e pelas exigências das agências reguladoras torna-se uma opção viável para promover o acesso da população brasileira aos medicamentos.

Todavia, no cotidiano dos pacientes, ainda permanecem práticas que dificultam o uso do medicamento genérico. Dentre elas, cita-se: a ausência do profissional habilitado, o farmacêutico, para exercer a dispensação e orientar o uso racional do medicamento; o papel exercido pelas estratégias de mercadização das indústrias farmacêuticas sobre a classe médica, que, principalmente em países em desenvolvimento, refletemse diretamente no incentivo ao uso irracional, indo de encontro à Política Nacional de Medicamentos ${ }^{26}$.

No dia a dia do paciente, a orientação do médico quanto ao uso do medicamento genérico revela-se de extrema importância. Podem advir, desse contato, a desconfiança e o preconceito em relação ao genérico, comprometendo o acesso aos medicamentos pela população de baixa renda. Os relatos a seguir demonstram esse fato:

Uma vez comprei o genérico e não gostei, parece que a pessoa acostuma com o remédio e se você mudar o nome você acha que aquele remédio não é o mesmo. A Novalgina pra mim faz um efeito, eu tomo Novalgina de manhã, o dia inteiro, não tenho nada. Estou tomando dipirona e acho que não está valendo de nada.

A médica mesmo não aconselha tomar o genérico, não, mas a gente compra, mesmo.

Não gosto do genérico. É leve.

A barreira financeira, portanto, pode vir a comprometer a qualidade dos serviços públicos de saúde prestados, pois a obtenção de tais insumos se constitui num dos pontos centrais do cuidado em saúde, principalmente quando se leva em consideração que a concretização desse acesso está associada ao uso efetivo dos medicamentos e, consequentemente, à satisfação dos usuários, representando, muitas vezes, o último vínculo destes com os serviços.

Nesse sentido, acredita-se que o acesso aos medicamentos no Brasil é um dos componentes para se fazer valer o direito à saúde assegurado no SUS. Stephan-Souza ${ }^{27}$ afirma que o estudo do acesso tende a tornar mais sólida a posição dos usuários dos serviços de saúde como sujeitos de direito, elemento central na afirmação da cidadania. A autora mencionada, ao mostrar que a análise do acesso aos serviços de saúde deve levar em consideração, a categoria cidadania/direitos sociais, entre outras, permite a ampliação desse entendimento para o acesso aos medicamentos.

Ademais, alguns estudos realizados afirmam que a definição formal dos direitos sociais, entre eles do direito à saúde, ampara-se na sua base legal, representando um conjunto de normas responsáveis pela regulação dos comportamentos sociais, requerendo a ação do Estado como meio de afirmá-lo através das políticas públicas. Dalla$\mathrm{ri}^{28}$, ao trabalhar com questões relacionadas ao direito social, destaca que, antes de tratar da responsabilidade do Estado em matéria de saúde, é preciso compreender o conceito de direito.

Outros estudos feitos sobre direitos sociais indicam que a apreensão destes deve perpassar pelo cenário público, como sustenta Telles ${ }^{3}$. Logo, os direitos sociais também podem ser entendidos como resultados das lutas, dos conflitos expressos em um espaço coletivo, isto é, a partir da dinâmica societária.

Segundo Nogueira e Pires ${ }^{29}$, os direitos sociais não devem ser entendidos como uma ficção jurídica, o que favorece o obscurecimento das críticas sobre sua não garantia, reduzindo seu potencial político de transformação socioetária. É preciso afastar-se da visão de um ideal de direito social que não se realiza no plano concreto. É preciso considerar a universalidade e a igualdade em sua expressão plena, evidenciando as formas de relações 
sociais estabelecidas e transitando entre o plano dos valores e da materialidade efetiva.

Nesse sentido, considera-se o campo da saúde como um local para a expressão concreta dos direitos sociais, pois é através da obtenção do acesso aos serviços de saúde e aos medicamentos que os usuários têm efetivamente o direito à saúde reconhecido.

No que diz respeito ao acesso aos medicamentos, percebe-se na fala de alguns usuários o não conhecimento do seu direito. Os seguintes depoimentos ilustram esse fato.

É um direito da pessoa que é pensionista ter em casa e ainda ajuda a pessoa que não é pensionista, que tem direito do remédio, e ele está ajudando um pouco porque nós não tínhamos isso, essa regalia.

Acho que é certo ele dar porque a maioria das pessoas não pode comprar mesmo. Porque as coisas hoje estão muito difíceis.

Eu acho que ele está sendo caridoso, ele tem que olhar para os pobres, que a vida é difícil, o dinheiro é pouco.

Esses relatos demonstram a influência exercida pela história da política de saúde do país no imaginário dos usuários. Esta foi primeiramente fundamentada na benesse, caracterizando-se pela oferta de atendimento "gratuito" dos serviços públicos de saúde à população necessitada. Também o acesso a esses serviços era viabilizado por meio de favores e de ações filantrópicas. Logo após, a política de saúde teve como base a contratualidade, ou seja, quem contribuía com a previdência social conseguia ter o ingresso assegurado nos serviços públicos de saúde.

Outra explicação para esses depoimentos é a noção tardia de direito social a que a população brasileira teve acesso. Isto influenciou a percepção dos usuários em relação ao acesso à saúde como direito social. No Brasil, a admissão do direito à saúde ocorreu tardiamente, a partir da Constituição Federal em 1988, exigindo para tornar-se efetivo a compreensão do direito, bem como da instituição e da delimitação dos deveres. Tal situação foi enfatizada por Dallari ${ }^{30}$.

Além disso, muitos usuários, principalmente os de idade mais avançada, vivenciaram as décadas anteriores à Constituição. Logo, ao demandarem por atendimento, muitas vezes não se sentem como um cidadão em busca da satisfação das necessidades básicas e à procura do reconhecimento do direito à saúde, que lhes pertence.

Uma minoria dos usuários do SUS reconhece essa busca por tais insumos como direito à saúde, justificando esse direito pelos baixos salários recebidos, pelas altas taxas de impostos a que são sub- metidos, pelas obrigações de campanha dos políticos e pelos aumentos abusivos dos salários do Executivo e, particularmente, do Judiciário e do Legislativo. Os relatos a seguir demonstram que, apesar de terem a compreensão do direito, os usuários não sabem politicamente o que representa esse direito, eles apenas reproduzem alguns jargões:

Eles não estão fazendo mais do que a obrigação deles, mesmo porque eu acho que a renda do nosso país é muito mal distribuída, está sobrando de um lado e faltando muito do outro, porque tem gente aí que está passando muita necessidade mesmo, porque o mercado está muito caro, a vida está muito cara.

Acho que é um direito. Pelo tempo que nós todos temos de contribuição, de aposentadoria. Fora os impostos que a gente paga, imposto disso, imposto daquilo, imposto pra respirar.

O governo não está fazendo nada demais, tanta facilidade que eles encontram para roubar. Isso éo minimo que eles podem fazer.

Em alguns casos, os usuários das UBS se apoiam na Constituição de 1988, a fim de fundamentar a concepção de direitos que têm, como demonstram os relatos a seguir:

Está lá na Constituição.

Ele não está fazendo favor nenhum, ele está fazendo uma obrigação do Executivo, Legislativo e Judiciário, a visão deles tem que ter isso, educação, saúde, moradia, e isso é obrigação dele fazer isso, não é favor, não. Não é bonzinho, não, ele não ganhou a segunda vez porque é bonzinho, não, nada disso. Isso aí é um dever de todos, não só dele, mas de toda pessoa que elegeu, porque ele foi eleito pra isso.

Porque é um direito adquirido, primeiro que todo cidadão tem direito a saúde, educação, como qualquer coisa.

Os depoimentos analisados permitem afirmar que se torna necessário repensar o papel do Estado como agente responsável pela implementação de uma política pública de saúde fundamentada nos critérios de universalidade e equidade. Só assim o cenário da saúde será concretamente um espaço de cidadania.

\section{Considerações finais}

O estudo do acesso aos medicamentos na percepção do usuário do Hiperdia, sob o enfoque dos direitos sociais, aponta para o abismo existente entre o SUS legal e o real. Percebeu-se na convivência diária com os usuários das UBS o quanto se torna difícil assegurar o direito à saúde garantido aos usuários. 
A natureza dos dados qualitativos analisados nesta pesquisa sugere que o cenário medicalizado e simbólico em que se encontra a saúde na sociedade brasileira contemporânea contribui para as diversas interpretações dos usuários das UBS em relação às doenças que os acometem $\mathrm{e}$ ao significado do medicamento. Além disso, a análise desses dados demonstra a percepção que os usuários têm sobre o acesso ao medicamento, sob o enfoque dos direitos sociais.

A maioria dos usuários se sente alheia a esse direito, demonstrando gratificação, conformismo e passividade diante do que lhes é oferecido. Isso conduz a uma situação de destituição de direito, de não pertencimento à sociedade, que pôde ser observada através das expressões e das falas dos usuários ao saírem dos consultórios após o atendimento médico, ou conseguirem ter acesso à medicação prescrita, evidenciada pelo sorriso nos lábios e pelo agradecimento à atendente da farmácia. Quando não conseguem obter alguns dos medicamentos contidos na receita, os usuários não questionam o motivo pelo qual não receberam o remédio, demonstrando o desconhecimento dos seus direitos. Grande parte percebe-se como beneficiária, isto é, considera o acesso aos serviços de saúde e aos medicamentos como benesse.

Logo, entende-se que, apesar do avanço ocorrido no setor da saúde propiciado pela criação do SUS, a concepção de acesso aos medicamentos como direito social ainda está longe de ser efetivada no cotidiano dos serviços públicos de saúde.
Nessa perspectiva, uma política de medicamentos visando ao acesso de toda a população brasileira aos medicamentos essenciais não pode se resumir simplesmente aos atos de adquirir, distribuir e entregar os medicamentos sem levar em consideração os problemas advindos principalmente da política econômica, que tem ocasionado limites na operacionalidade da política de seguridade social como a previdência, a assistência e a saúde, encontrando-se distante de oferecer respostas à questão social no que concerne à desigualdade, ao desemprego e à destituição de direitos.

Esses elementos afetam diretamente o acesso da população aos medicamentos essenciais e apontam para a construção de uma cidadania que deixa muito a desejar, de ações focalizadas, em que a inclusão social ocorre pela defesa do acesso ao consumo. No campo da saúde, esse acesso é evidenciado pelo poder de compra de alguns usuários, no que diz respeito à saúde $\mathrm{e}$ aos medicamentos, beneficiando o processo de medicalização e o acesso desigual aos serviços de saúde e aos medicamentos na sociedade brasileira contemporânea.

Logo, a apreensão da percepção dos usuários sobre o acesso aos medicamentos como direito social é indispensável para que o campo da saúde se efetive como espaço de afirmação e de reconhecimento dos direitos sociais, como espaço de cidadania.

\section{Colaboradores}

PAB Paula trabalhou na concepção teórica, execução da pesquisa, coleta e análise dos dados, discussão dos resultados e considerações finais. AI Stephan-Souza e RCPA Vieira participaram da revisão bibliográfica, análise dos dados, discussão dos resultados e considerações finais. 


\section{Referências}

1. Brasil. Senado Federal. Constituição da República Federativa do Brasil. Brasília: Senado Federal; 1988.

2. Bahia L. Contradições do SUS. In: Seminário de Saúde Brasileira; 2006; Juiz de Fora. (Palestra proferida na Universidade Federal de Juiz de Fora, promoção do Mestrado em Saúde Brasileira).

3. Telles VS. Direitos sociais: afinal, do que se trata? Belo Horizonte: UFMG; 1999.

4. Illich I. A expropriação da saúde: nêmesis da medicina. Rio de Janeiro: Nova Fronteira; 1975.

5. Barros JAC. Políticas farmacêuticas: a serviço dos interesses da saúde? Brasília: Unesco; 2004.

6. Brasil. Ministério da Saúde. Acesso aos medicamentos essenciais. [documento na Internet]. [acessado 2006 jan 3]. Disponível em: www.saude.gov.br

7. Brasil. Datasus. Sistema de Informação de Atenção Básica. [documento na Internet]. [acessado 2006 jan 17]. Disponível em: www.datasus.gov.br

8. Brasil. Ministério da Saúde. Organização Pan-Americana da Saúde. Organização Mundial da Saúde. Avaliação da assistência farmacêutica no Brasil. Brasília: Ministério da Saúde, Opas; 2005.

9. Lefèvre F. O medicamento como mercadoria simbólica. São Paulo: Cortez; 1991.

10. Zubioli A. Lei do medicamento. In: Bonfim JRA, Mercucci VL, orgaanizadores. A construção da politica de medicamentos. São Paulo: Hucitec; 1997.

11. Marin N, organizador. Assistência farmacêutica para gerentes municipais. Rio de Janeiro: Opas, OMS; 2003.

12. Minas Gerais. Juiz de Fora. Secretaria Municipal de Saúde e Desenvolvimento Ambiental. Serviço de Controle da Hipertensão, do Diabetes e da Obesidade (SCHDO). Juiz de Fora: Secretaria Municipal de Saúde e Desenvolvimento Ambiental; 2006.

13. Bogdan RC, Biklen SK. Investigação qualitativa em educação. Porto, Portugal: Porto Editora; 1994.

14. Turato ER. Conceitos de pesquisa qualitativa em saúde mental. In: Turato ER. Pesquisa qualitativa em saúde: múltiplos olhares. Campinas: Unicamp; 2005. p. 27-35.

15. Kitzinger J. Grupos focais com usuários e profissionais da atenção à saúde. In: Pope C, Mays N, organizadores. Pesquisa qualitativa na atenção à saúde. Porto Alegre: Artmed; 2006.

16. Minayo MCS. O desafio do conhecimento: pesquisa qualitativa em saúde. São Paulo: Hucitec; Rio de Janeiro: Abrasco; 1998.

17. Ferreira J. O corpo sígnico. In: Alves PC, Minayo MCS, organizadores. Saúde e doença: um olhar antropológico. Rio de Janeiro: Editora Fiocruz; 1994. p. 101-112.
18. Camargo Júnior KR. Biomedicina, saber e ciência: uma abordagem crítica. São Paulo: Hucitec; 2003.

19. Boltanski L. As classes sociais e o corpo. Rio de Janeiro: Graal; 1979.

20. Sociedade Brasileira de Endocrinologia. [site na Internet].2007 [acessado 2007 out 6] . Disponível em: http://www.sbend.org.br

21. Sociedade Brasileira de Hipertensão Arterial. [site na Internet]. 2007 [acessado 2007 out 6]. Disponível em: http://www.sbha.org.br

22. Oliveira MA, Bermudez JAZ, Osório de Castro CGS. Assistência farmacêutica e acesso a medicamentos. Rio de Janeiro: Editora Fiocruz; 2007.

23. Penchansky R, Thomas W. The concept of access: definition and relationship to consumer satisfaction. Medical Care 1981; 19(2):127-140.

24. Luiza VL. Acesso a medicamentos essenciais no Estado do Rio de Janeiro [tese]. Rio de Janeiro: Escola Nacional de Saúde Pública Sergio Arouca, Fundação Oswaldo Cruz; 2003.

25. Fischer-Pühler P. O acesso ao fármaco. In: Negri B, Viana ALD'A, organizadores. O Sistema Único de Saúde em dez anos de desafios. São Paulo: Sobravime, Celag; 2002.

26. Vieira RCPA. Propagandas de medicamentos distribuídas aos médicos: aspectos legais, farmacológicos e de mercadização [tese]. Rio de Janeiro: Instituto de Medicina Social, Universidade do Estado do Rio de Janeiro; 2004.

27. Stephan-Souza AI. O acesso na dimensão da universalidade e excludência: um estudo das demandas dos usuários do Hospital Universitário HU/ UFJF. Libertas 2001; 1(2):9-28.

28. Dallari SG. O papel do município no desenvolvimento de políticas de saúde. Rev Saude Publica 1991; 25(5):401-405.

29. Nogueira VMR, Pires DEP. Direito à saúde: um convite à reflexão. Cad Saude Publica 2004; 20(3):753760 .

30. Dallari GS. Os estados brasileiros e o direito à saúde. São Paulo: Hucitec; 1995.

Artigo apresentado em 25/08/2008

Aprovado em 19/01/2009

Versão final apresentada em 25/02/2009 